\title{
Políticas de ciencia y tecnología y el Sistema Nacional de Innovación en la Argentina
}

\section{Daniel Chudnovsky}

Director del Centro de

Investigaciones

para la Transformación (CENIT).

Profesor titular de

desarrollo económico,

Universidad de Buenos Aires
Este artículo examina las fortalezas y debilidades de las políticas planteadas en el Plan Nacional Plurianual de Ciencia y Tecnología 1998-2000 de Argentina, dentro del marco conceptual que brinda el enfoque del Sistema Nacional de Innovación (SNI). A partir de un diagnóstico severo de las debilidades del esfuerzo argentino en este campo, las nuevas políticas públicas apuntan a promover la interacción de los numerosos agentes e instituciones que participan en dicho esfuerzo, a modificar las reglas del juego en la asignación de los recursos públicos a la investigación, a promover planes estratégicos y mecanismos de evaluación en los organismos públicos del área y a inducir un mayor gasto endógeno del sector privado a través del crédito fiscal a la investigación y el desarrollo tecnológico y de un Programa de Consejeros tecnológicos para atender mejor las demandas de las pequeñas y medianas empresas. Sin embargo, son muy profundas las fallas del sistema financiero argentino para financiar inversiones de largo plazo en activos intangibles, las del sistema educativo para vincularse con las necesidades del sector productivo y las de las instituciones científicas para interactuar con el sistema educativo y el productivo. Estas fallas, si bien se mencionan en el Plan, no reciben la atención que se requiere para comenzar a revertirlas. La larga y frustrante historia previa de las políticas de ciencia y tecnología en el país, que exhiben más fracasos que éxitos, y el éxito parcial del laissez faire en los años noventa, considerado una buena política por la mayoría del gran empresariado local y extranjero, conspiran contra el éxito de las iniciativas en marcha. Al mismo tiempo y pese a sus sugerentes planteos, el enfoque del SNI revela profundas ambigüedades normativas y conceptuales que restringen su aplicabilidad práctica. 


\section{I}

\section{Introducción}

En diciembre de 1997 el Gabinete Científico Tecnológico del gobierno (GACTEC) aprobó el Plan Nacional Plurianual de Ciencia y Tecnología 1998-2000 (Argentina, GACTEC, 1997), en adelante el Plan, cuyo objetivo central es nada menos que "el desarrollo y fortalecimiento del Sistema Nacional de Ciencia, Tecnología e Innovación" (Argentina, GACTEC, 1997). Por la primera vez en la Argentina se planteaba a nivel oficial el enfoque del Sistema Nacional de Innovación (SNI), así como es casi una novedad el hecho de que se haya elaborado un plan de ciencia y tecnología. ${ }^{1}$

El Plan fue el resultado de una serie de cambios institucionales que se pusieron en marcha en julio de 1996, cuando la Secretaría de Ciencia y Tecnología pasó a depender nuevamente del Ministerio de Cultura y Educación y se inició una reorganización del sector científico-tecnológico.

Luego de un intenso debate que se reflejó en el documento "Bases para la discusión de una política de ciencia y tecnología", elaborado por una centena de expertos, a fines de año se creó el GACTEC, presidido por el Jefe de Gabinete de Ministros e integrado por los ministros de Economía, Educación, Salud, Relaciones Exteriores y Defensa y la Secretaría de Recursos Naturales y Desarrollo Sustentable. La secretaría ejecutiva del GACTEC es ejercida por la Secretaría de Ciencia y Tecnología.

También a fines de 1996 se creó la Agencia Nacional de Promoción de la Ciencia y la Tecnología (a la que en adelante llamaremos la Agencia), dedicada exclusivamente a financiar proyectos de investigación en el sector público y privado sin fines de lucro y a promover la innovación tecnológica en el sector pri-

$\square$ Versión revisada del estudio preparado para el Proyecto OEA-MCT de Brasil "Globalización e innovación localizada: Experiencias de sistemas locales en el ámbito del Mercosur y propuestas de políticas de ciencia y tecnología". Se agradecen los comentarios de Juan Carlos Del Bello y Jorge Katz a una versión preliminar, obviamente sin comprometerlos con nuestras apreciaciones. La información utilizada era la disponible a principios de 1998; el Plan Nacional Plurianual de Ciencia y Tecnología 1999-2001, de próxima aparición, ofrecerá una actualización de los datos y de las políticas seguidas.

${ }^{1}$ El antecedente previo se remonta a 1971, año en que la Secretaría del Consejo Nacional de Ciencia y Técnica elaboró un Plan Nacional de Ciencia y Técnica 1971-1975. vado. En octubre de 1997 el GACTEC elaboró el Plan que acompañó al proyecto de ley de presupuesto nacional para 1998 y simultáneamente lo lanzó a la discusión pública.

Este dinamismo contrasta fuertemente con el laissez faire en política tecnológica (y en cierta medida en política científica) practicado no sólo por el gobierno de Menem hasta 1996, sino también por los gobiernos argentinos previos tanto civiles como militares (véase Adler, 1987, respecto a los años sesenta y setenta. $^{2}$

Mientras que hasta 1990 el laissez faire se daba fundamentalmente por omisión y en situaciones macroeconómicas poco proclives al crecimiento, en un trabajo previo argumentábamos que en la actual administración éste encontraba sus fundamentos en la teoría económica ortodoxa o corriente económica principal (Chudnovsky y López, 1995). Dicha teoría considera a la ciencia y la tecnología básicamente como variables exógenas ${ }^{3}$ y, en general, adhiere a las recomendaciones de política del denominado Consenso de Washington (Williamson, 1990), que privilegian la liberalización comercial, la privatización de empresas públicas y la promoción de la inversión extranjera directa (IED) como instrumentos fundamentales para lograr la modernización tecnológica en países en desarrollo.

Según la corriente económica principal, la apertura de la economía a las importaciones estimularía una mejora en la eficiencia del sector productivo a través de la mayor competencia en el mercado local; al mismo tiempo, facilitaría el acceso a maquinaria y equipo de última generación, cuya importación se vio favore-

\footnotetext{
${ }^{2}$ Las excepciones más marcadas a esta tendencia histórica se registraron en la segunda mitad de los años cincuenta, cuando se crearon la Comisión Nacional de Energía Atómica (CNEA), el Instituto Nacional de Tecnología Agropecuaria (INTA), el Instituto Nacional de Tecnología Industrial (INTI) y el Consejo Nacional de Investigaciones Científicas y Técnicas (CONICET); entre 1969 y 1975, cuando se creó el Consejo Nacional de Ciencia y Técnica y se dictaron leyes sobre transferencia de tecnología, y en mucho menor medida en 1984-1989, cuando se planteó una política informática y se constituyó la Oficina de Transferencia de Tecnología en el CONICET, entre otras iniciativas (Chudnovsky y López, 1995).

${ }^{3}$ Sólo en los últimos años se ha comenzado a incorporar el cambio tecnológico como variable endógena en los modelos de crecimiento económico (por ej., en los trabajos de Paul Romer).
} 
cida por el arancel cero vigente hasta poco tiempo atrás en la Argentina. La privatización de las empresas públicas no sólo las haría más eficientes en la provisión de bienes y servicios: al eliminar las cláusulas de "compre nacional", induciría también una mayor competencia entre los proveedores de dichas empresas.

A su vez, la liberalización del régimen de IED promovería la incorporación y difusión de los conocimientos técnicos y gerenciales de los inversores extranjeros. Asimismo, la desregulación de los acuerdos de transferencia de tecnología sería otro estímulo al proceso de modernización tecnológica.

Estas políticas han sido sin duda las que han tenido mayor impacto sobre la modernización tecnológica del país entre las adoptadas por el actual gobierno. En una economía con precios estables y en rápido crecimiento, el fuerte aumento de las importaciones de bienes de capital y de los flujos de IED, así como el sustancial crecimiento de la productividad del trabajo en los años noventa, darían cuenta del éxito de las políticas aplicadas.

Sin embargo, el hecho de que buena parte del aparato productivo tenga muchas dificultades para acercarse a las mejores prácticas tecnológicas internacionales y de que, pese al aumento del gasto en ciencia y tecnología en los años noventa, ${ }^{4}$ la crisis de las instituciones públicas dedicadas a estas actividades les impide definir sus objetivos y prioridades de investigación en función de las demandas económicas y sociales del país, refleja el papel marginal que tiene el esfuerzo endógeno científico-tecnológico en las políticas vigentes.

La creciente difusión que han tenido enfoques teóricos distintos de los ortodoxos entre quienes definen la política tecnológica en los países de la Organización de Cooperación y Desarrollo Económicos (OCDE) ha creado un marco propicio a una visión de los problemas de la modernización tecnológica y de las políticas para impulsarla que difiere bastante de la planteada por la corriente económica principal y por el Consenso de Washington. ${ }^{5}$

\footnotetext{
${ }^{4}$ El gasto en ciencia y tecnología como porcentaje del producto interno bruto (PIB) aumentó de alrededor de 0.33 en 1985-1990, a 0.40 en 1994 y a 0.46 en 1996 (Argentina, GACTEC, 1997).

5 Aunque Williamson (1997) ha modificado algunas de las reco-
}

Dado que en los complejos fenómenos de adquisición, adaptación y desarrollo de tecnología los mercados no existen o evidencian serias fallas, la transmisión de la información y de los conocimientos es imperfecta y las empresas actúan con racionalidad acotada, las políticas públicas tienen un papel importante que cumplir en este campo especialmente en lo que respecta a las pequeñas y medianas empresas (PYME), que son las que más dificultades tienen para adaptarse a las nuevas condiciones de competencia.

Por otra parte, si bien la importación de maquinaria y equipo y el ingreso de IED facilitan la modernización tecnológica, y los aspectos codificables del conocimiento tecnológico dan lugar a transacciones mercantiles, el proceso en cuestión genera una serie de externalidades positivas y sinergias que no se expresan a través del mercado y que pueden requerir instancias de coordinación y promoción por parte de los gobiernos nacionales y locales, lo cual significa, obviamente, dejar de lado el laissez faire.

Esta visión del problema había sido ya impulsada por algunos funcionarios del actual gobierno en iniciativas aisladas como la Ley 23877 de Promoción y Fomento de la Innovación Tecnológica, sancionada en 1990 y reglamentada en 1992, y en el Programa de Modernización Tecnológica cofinanciado con el Banco Interamericano de Desarrollo, que se puso en ejecución en 1994. Con los cambios institucionales recientes y el lanzamiento del Plan, se ha dado jerarquía a una política activa y, en principio, mucho más articulada en la materia.

El reciente dinamismo gubernamental en este terreno es sin duda un hecho auspicioso, porque intenta comenzar a revertir la profunda crisis en la que se encuentran las principales instituciones y organismos públicos dedicados a la ciencia y la tecnología, y a incentivar al sector privado para que haga mayores esfuerzos en este campo. En tal sentido, este artículo apunta a examinar las principales políticas planteadas en el Plan y señalar sus fortalezas y debilidades, desde el marco conceptual que brinda el enfoque del sNI. mendaciones originalmente planteadas en el Consenso de Washington, en especial la política cambiaria y la forma de ejecutar la liberalización comercial, la problemática de la política tecnológica no ha sido incorporada en las nuevas recomendaciones. 


\section{II}

\section{El marco conceptual}

En el enfoque de la corriente económica principal, la tecnología intangible se corporiza en un código de conocimientos generado por los departamentos de investigación y desarrollo (I y D) de firmas especializadas. Estos departamentos utilizan en mayor o menor medida los conocimientos científicos que se generan en las universidades e institutos públicos de I y $\mathrm{D}$.

En la lógica del enfoque lineal de la política científica y tecnológica (OCDE, 1992), que se inspira en parte en la corriente económica principal, los resultados de los esfuerzos de I y D en el sector público se derraman hacia los usuarios como bienes públicos. En las empresas privadas los esfuerzos innovativos se generan en los departamentos de I y D, de ahí se difunden internamente a los departamentos de producción y de comercialización y llegan al mercado en forma de innovaciones de productos y procesos.

En la medida en que los conocimientos estén codificados, sus usuarios pueden reproducir las instrucciones respectivas sin mayores dificultades. En consecuencia, la tecnología constituiría un factor exógeno para la mayor parte de las empresas. Si está bajo dominio privado, vía patentes de invención u otros mecanismos, se la adquiriría en el mercado a través del pago de regalías u otras contraprestaciones. Si es de libre disponibilidad, simplemente se conseguiría como información técnica.

En los enfoques mencionados, los principales objetivos de la política científica y tecnológica pasan por asegurar una corriente continua de innovaciones -mediante un adecuado financiamiento estatal a la investigación científica y tecnológica que se hace en universidades y laboratorios públicos, la protección a la propiedad intelectual y los incentivos fiscales a los gastos en I y D que realiza el sector privado- y por favorecer la difusión de las innovaciones en el tejido productivo mediante un eficiente sistema de información, dirigido principalmente a las PYME. Las conductas monopólicas a las que podría dar lugar la utilización de los activos intangibles serían contrarrestadas con una política de defensa de la competencia.

En contraste con el enfoque de la corriente económica principal, para las teorías evolutivas o neoschumpeterianas los conocimientos científicos y tecnológicos no son perfectamente codificables y, por ende, su transferibilidad es imperfecta. Tanto para generar conoci- mientos como para poder utilizarlos se requiere un esfuerzo endógeno basado en la acumulación de capacidades científicas, técnicas y organizacionales, el cual a su vez da lugar a aumentos de la productividad y la eficiencia y, por ende, a la generación de un flujo creciente de innovaciones en materia de productos y procesos de producción.

La noción de capacidades tecnológicas intenta capturar la gran variedad de conocimientos y habilidades requeridos para comprar, asimilar, usar, adaptar, cambiar y crear tecnologías. Este concepto va más allá de las nociones tradicionales de ingeniería y know how técnico, para incluir el conocimiento tanto de los procedimientos y estructuras organizacionales como de los patrones de comportamiento, por ejemplo, de trabajadores o clientes. Las firmas necesitan ciertos activos complementarios para crear, movilizar y mejorar sus capacidades tecnológicas, entre los cuales se pueden incluir flexibilidad organizacional, recursos financieros, calidad de los recursos humanos y sofisticación de los servicios de apoyo y de información (OCDE, 1992).

El proceso de adquirir los conocimientos científicos, técnicos y organizacionales que permitan utilizar eficientemente las tecnologías disponibles es prolongado, riesgoso e impredecible. Implica desarrollar capacidades tecnológicas y de organización mediante esfuerzos deliberados de aprendizaje en el proceso de producción (learning by doing), en la comercialización y en el contacto con los clientes (learning by using) y en la búsqueda incesante de nuevas soluciones técnicas en las unidades de I y D o en instancias menos formales, como las oficinas técnicas (learning by searching). Además de importantes esfuerzos intramuros, este proceso implica interactuar con los proveedores de equipos, partes y componentes, con los licenciantes, con los socios extranjeros, con institutos tecnológicos y universidades y con clientes (learning by interacting). Se trata de un proceso colectivo de aprendizaje en el cual, si bien el epicentro está constituido por las propias empresas manufactureras y los diferentes sectores en donde ellas actúan, se encuentran involucrados también otros actores e instituciones públicas y privadas.

El carácter tácito, localizado y acumulativo del conocimiento tecnológico, el énfasis en el proceso de 
aprendizaje y en las distintas fuentes que lo motivan, así como la importancia de la retroalimentación y de las numerosas interacciones que lo caracterizan e inducen, ponen de relieve un complejo y dinámico cuadro social que difiere completamente del esquema simplificado con que aborda el tema la literatura de la corriente económica principal.

Los numerosos actores e instituciones que participan en el proceso de innovación, y la importancia de la interacción de aquéllos para lograr un desempeño innovativo que rinda frutos en términos de beneficios privados y sociales, han sido bien captados en la literatura neoschumpeteriana a través del concepto de sistema nacional de innovación.

La primera definición de este sistema, sugerida por Freeman (1988), lo identificaba con la de red de instituciones en el sector público y privado cuyas actividades e interacciones inician, importan, modifican y difunden nuevas tecnologías. En un trabajo posterior el autor plantea que fue List el primero que utilizó dicho enfoque, aunque lo denominara de otra forma (Freeman, 1995). En los libros editados por Lundvall (1992), por Nelson (ed., 1993) y por Edquist (ed., 1997) el SNI es analizado desde diversos ángulos y sobre la base de distintas experiencias nacionales. Al mismo tiempo, el concepto de SNI se fue extendiendo del mundo académico al de los hacedores de política $\mathrm{y}$, de una u otra forma, se está utilizando tanto en los documentos de la OCDE (1992 y 1996b) como de varios de sus países miembros.

En Edquist (1997) se hace un excelente estudio del enfoque basado en el sNI. A nuestro juicio, de la elaboración de Edquist nos parece muy correcta su apreciación de que se trata no de una teoría formal, sino de un marco conceptual para abordar la problemática que nos preocupa, desde un enfoque holístico, interdisciplinario e histórico, aunque conceptualmente difuso.

En forma sucinta, el punto fuerte de un enfoque basado en el SNI es el de considerar la innovación y el aprendizaje como aspectos cruciales. Si bien las empresas son la espina dorsal del SNI, las empresas no innovan solas. La innovación es un proceso interactivo $y$, por ende, el enfoque hace hincapié en la importancia de las interacciones de los distintos actores e instituciones que participan en el complejo proceso colectivo. A diferencia del modelo lineal que subrayaba esencialmente la generación de innovaciones, en el SNI se pone tanto o más énfasis en la difusión que en la generación de innovaciones.

Aunque existen diferencias de apreciación entre los autores, los enfoques basados en el SNI se refieren a innovaciones mayores y menores de productos, de procesos y organizacionales. Por otra parte, no sólo abarcan innovaciones en los países que están en la frontera tecnológica sino también en aquellos que siguen la estrategia de dar alcance a las economías más avanzadas y mantenerse a su nivel (Mytelka, 1996).

Al mismo tiempo, estos enfoques tratan de escapar a la usual dicotomía de abordar el problema en función de sólo dos instituciones fundamentales -el mercado y el Estado- y toman en cuenta además, entre muchas otras, las universidades, los bancos, la legislación de la propiedad intelectual y los institutos de investigación y de servicios tecnológicos.

Además de las enormes dificultades que se presentan al tratar de identificar y cuantificar los distintos indicadores que, más allá de los gastos en I y D y el número de patentes de invención, darían cuenta del funcionamiento de un SNI, los puntos más débiles de este enfoque están vinculados al peso relativo de los insumos que vienen del exterior respecto de los esfuerzos endógenos de absorción ${ }^{6}$ y generación de innovaciones y, sobre todo, a sus aspectos normativos en cuanto al papel de las políticas públicas en la conformación de los SNI.

En una economía globalizada en donde la IED crece más rápidamente que el comercio internacional y donde los costos de transmisión de la información y de transporte se reducen cada vez más, los flujos externos de conocimientos tecnológicos adquieren creciente relevancia. No obstante, en la medida en que los conocimientos que se generan en los procesos innovadores son tácitos, acumulativos y localizados, existiría un espacio importante a nivel nacional y local para el desarrollo de capacidades tecnológicas endógenas. Dichas capacidades son imprescindibles, como mínimo, para poder absorber en forma eficiente lo que viene de afuera y, obviamente, para poder adaptar, modificar y generar nuevos conocimientos.

A pesar de la creciente interdependencia de los países industrializados en lo referente a flujos de inversión y de tecnología, los estudios piloto sobre SNI realizados en varios países de la OCDE ponen de relieve que las empresas basan su proceso innovador fundamentalmente en sus propios esfuerzos de I y D y re-

\footnotetext{
${ }^{6}$ Este tema fundamental es ignorado en el estudio de Edquist (1997). Sin embargo, en la nota de pie de página 44 de su obra citada dice que para todos los países, salvo los más grandes desde el punto de vista económico, esta difusión [de tecnología] significa principalmente absorción desde el exterior. Así sucede tanto en Suecia como en México y la India..
} 
curren relativamente poco a flujos importados (OCDE, 1996a).

En contraste, la mayor parte de los países en desarrollo exhiben en general la situación opuesta. No sólo son relativamente escasos los recursos asignados a I y D en el sector privado, sino que las firmas interactúan mucho más con proveedores tecnológicos del exterior que con firmas o instituciones locales. Asimismo, los vínculos tienen en general carácter unidireccional (licencias, franquicias, subcontratación) y son escasos los acuerdos bidireccionales en materia de I y $\mathrm{D}$, de producción o de comercialización (siguiendo la clasificación propuesta por Mytelka, 1992).

Por otra parte, en los países asiáticos que han seguido una estrategia exitosa de ir dando alcance a economías más avanzadas en la materia se observa que, si bien los esfuerzos por absorber tecnologías provenientes del exterior en la estrategia de industrialización han sido generalizados, los canales utilizados han diferido notablemente entre ellos, así como entre los sectores industriales elegidos en las distintas etapas de la estrategia (Mowery, 1993; Lall, 1992).

Las opiniones de diversos autores respecto al papel de las políticas públicas en la conformación de los SNI difieren notablemente. Mientras que Nelson y Rosenberg consideran que los SNI evolucionan espontáneamente $\mathrm{y}$, por ende, no son diseñados en forma consciente, otros autores sostienen que el Estado tiene un rol importante en su conformación. La posición de Edquist parece la más plausible: algunos elementos del SNI evolucionan espontáneamente y otros son objeto de políticas públicas deliberadas. Asimismo, el autor considera que el enfoque del SNI es útil para la formulación de políticas en la medida en que provee un marco de análisis para identificar cuestiones específicas de política que es distinto del que surge de la economía ortodoxa.

De todas formas, del enfoque del SNI no dimanan elementos normativos demasiado precisos para la formulación de políticas. Autores como Nelson y Dahlman estarían básicamente de acuerdo con las recomendaciones del Consenso de Washington en cuanto al papel positivo de la IED y la apertura comercial, pero lo complementarían con políticas horizontales que tiendan a aumentar la capacidad tecnológica y de absorción social de conocimientos (Dahlman y Nelson, 1993). En contraste, otros autores como Freeman y, sobre todo, Lall le asignarían mucha mayor importancia a las políticas selectivas en materia industrial y tecnológica (Lall, 1995).

En lo que respecta a los países de industrialización tardía, no hay duda de que la experiencia japone- sa primero y la de los tigres asiáticos después ha sido una fuente de inspiración acerca de lo que deberían ser los SNI relativamente exitosos. Sin embargo, si bien dicha inspiración es nítida en los trabajos de Freeman (1988 y 1995) y Lall (1992 y 1995), es mucho menos evidente en los estudios de Nelson.

Como señalan David y Foray (1995), desde el punto de vista social importa el "poder distributivo" de un SNI, lo que apunta a facilitar una eficiente distribución y utilización del conocimiento científico y tecnológico disponible en la sociedad. Esto supone que los mismos medios que se usan para asegurar una mayor rentabilidad privada de las actividades innovadoras pueden disminuir el poder distributivo del SNI. Por consiguiente, puede surgir un conflicto entre "apropiabilidad", que favorecería una mayor acumulación de nuevo conocimiento y "poder distributivo", que contribuiría a que ese conocimiento fuese socialmente más "útil".

De ahí que, en el caso de los países industrializados, la oCDE haya señalado correctamente que el dilema para las políticas públicas es tener que conciliar dos grandes objetivos. Por un lado, deben desarrollar un ambiente que sea rico en incentivos, de modo que los beneficios privados esperados sean significativos y motiven a las empresas a generar cada vez más innovaciones. Los incentivos en cuestión no sólo deben consistir en deducciones fiscales a los gastos de I y D y la protección de la propiedad intelectual, sino abarcar también el financiamiento de la investigación precompetitiva, la promoción de alianzas estratégicas y las adquisiciones del sector público, entre otros aspectos.

Por otro lado, deben fomentarse numerosos derrames, de forma que las firmas se apropien sólo parcialmente de los beneficios de la innovación y se maximicen las rentabilidades sociales de ella. Esto implica una serie de acciones que no sólo incluyen la defensa de la competencia, sino también medidas para fomentar los vínculos interempresas y entre empresas, universidades e institutos de investigación a nivel regional; la provisión de servicios de asesoramiento y consultoría a las PYME; la labor de las incubadoras de empresas y los programas de adiestramiento y readiestramiento de personal técnico y gerencial (OCDE, 1992 y 1997).

En conclusión, aunque conceptualmente difuso, el enfoque del SNI es ciertamente valioso para abordar y pensar la problemática de la innovación en países desarrollados y en desarrollo. Destaca los agentes e instituciones más importantes que hay que tener en cuenta en la conformación de los SNI y es lo suficientemente 
flexible como para adecuarse a las diversas realidades históricas e institucionales. No obstante, aunque sugiere las áreas en que las políticas públicas deberían actuar y, en general, rechaza el laissez faire, está lejos de brindar recomendaciones específicas respecto de las políticas que habría que seguir.

\section{III}

\section{Las nuevas políticas de ciencia y tecnología en Argentina}

\section{El diagnóstico}

Aunque sin entrar en sus causas, en el Plan se hace un diagnóstico severo de la situación argentina en materia de ciencia y tecnología, diagnóstico que, en general, compartimos y que se resume a continuación.

En primer lugar, el notable proceso de crecimiento reciente de la economía argentina (casi $6 \%$ anual como promedio entre 1990 y 1996) y de la productividad del trabajo (47\% entre 1990 y 1996) ${ }^{7}$ se ha basado en maquinaria, insumos y conocimientos que provienen principalmente del exterior. Los datos sobre importaciones de bienes de capital, inversión extranjera directa y patentes de invención lo ilustran claramente.

Las importaciones de maquinaria y equipo crecieron de 635 a 6037 millones de dólares entre 1990 y 1994, se redujeron un $20 \%$ en 1995 y siguieron una tendencia ascendente en 1996 y 1997. ${ }^{8}$ Las corrientes de IED aumentaron de un promedio anual de 2700 millones de dólares en 1990-1993, cuando estaban dirigidas básicamente a la adquisición de empresas estatales, a 3800 millones en 1994-1996, cuando la industria, la minería y algunos servicios atrajeron la mayor parte de dichas corrientes. Las solicitudes de patentes de invención presentadas en la Argentina por no residentes aumentaron de 1955 en 1990 a 4012 en 1996. De un promedio anual superior a las mil solicitudes en

\footnotetext{
7 Según información oficial la productividad del trabajo en la industria creció un 58\% (6.8\% anual) desde 1990 al primer semestre de 1997, mientras que en los años ochenta creció al $0.8 \%$ anual en promedio (CEP, 1997).

${ }^{8}$ La inversión interna fija bruta aumentó de un $13.4 \%$ al $23.6 \%$ del PIB entre 1990 y 1994. El coeficiente de inversión se redujo a un $20.7 \%$ en 1995, se recuperó en 1996 (21.5\%) y se estima que alcanzó un $25 \%$ del PIB en 1997. Dentro de esta inversión los bienes de capital importados pasaron de representar el $13 \%$ en el primer trimestre de 1991 a un $40 \%$ en el primer trimestre de 1997. Los bienes de capital nacionales redujeron su participación de 20 a $12 \%$ entre las fechas mencionadas (Argentina, Ministerio de Economía y Obras y Servicios Públicos, Secretaría de Política Económica, 1997).
}

los años ochenta y de más de 900 a principios de los noventa, las solicitudes de residentes bajaron a menos de 700 en 1994 y 1995 y llegaron a 1097 en 1996. A la vez, los residentes argentinos casi no patentan en el exterior.

De ahí que en el Plan se indica que el significativo proceso de crecimiento económico en los años noventa ha generado escasas oportunidades para utilizar el acervo de recursos humanos del país. Ha dejado de lado a buena parte de las PYME, que muestran serias debilidades para adaptarse a las nuevas reglas del juego de la economía argentina, y no ha generado incentivos suficientes para que las grandes firmas hagan esfuerzos sistemáticos de investigación, desarrollo e innovación.

Como se puede observar en el cuadro 1, el gasto en ciencia y tecnología del sector privado está totalmente fuera de la escala internacional. Se lo ha estimado en $0.13 \%$ del PIB, porcentaje muy inferior no sólo al de los países industrializados (que supera el 1\%) sino también al de Chile y Brasil $(0.27$ y $0.18 \%$, respectivamente).

Aunque buena parte de los insumos para la innovación en materia de productos y procesos de producción proviene del exterior, es de suponer que la competencia más intensa que se ha registrado en la economía argentina en los últimos años esté induciendo actividades de innovación y esfuerzos tecnológicos endógenos de cierta envergadura para absorber y adaptar conocimientos. Se estima que el sector de empresas ha acrecentado su gasto en I y D, en pesos constantes de 1996, de 214 millones en 1993 a 369 millones en 1996 (de $0.8 \%$ a $0,13 \%$ del PIB). ${ }^{9}$

\footnotetext{
${ }^{9}$ Como se supone que esta estimación no da cuenta de todos los esfuerzos innovativos que probablemente estén ocurriendo en la mayor parte de las grandes empresas extranjeras o nacionales y en las pequeñas y medianas firmas, la Secretaría de Ciencia y Tecnología está realizando una encuesta sobre la conducta tecnológica de las empresas industriales argentinas a través del Instituto Nacional de Estadística y Censos (INDEC).
} 
CUADRO 1

Comparación internacional de la inversión en ciencia y tecnología

\begin{tabular}{|c|c|c|c|c|c|c|}
\hline \multirow[t]{2}{*}{ País } & \multicolumn{2}{|c|}{$\begin{array}{c}\text { Inversión total } \\
\text { en ciencia y tecnología }\end{array}$} & \multicolumn{2}{|c|}{ Gobierno y otros ${ }^{b}$} & \multicolumn{2}{|c|}{ Empresas } \\
\hline & Millones de dólares & $\%$ del PIB & Millones de dólares & $\%$ del PIB & Millones de dólares & $\%$ del PIB \\
\hline Estados Unidos & 184300 & 2.48 & 66822 & 0.87 & 117478 & 1.53 \\
\hline Japón & 76004 & 2.78 & 22573 & 0.82 & 53431 & 1.96 \\
\hline Alemania & 37149 & 2.48 & 14785 & 0.99 & 22363 & 1.49 \\
\hline Francia & 26721 & 2.38 & 11788 & 1.05 & 14933 & 1.33 \\
\hline República de Corea & 12200 & 2.69 & 3282 & 0.72 & 8918 & 1.97 \\
\hline España & 4376 & 0.92 & 2464 & 0.52 & 1912 & 0.40 \\
\hline Brasil $^{\mathrm{c}}$ & 5888 & 0.87 & 4107 & 0.61 & 1850 & 0.27 \\
\hline México $^{c}$ & 1114 & 0.33 & 1039 & 0.31 & 75 & 0.02 \\
\hline Argentina ${ }^{c}$ & 1353 & 0.46 & 984 & 0.33 & 369 & 0.13 \\
\hline Chile $^{\mathrm{c}}$ & 398 & 0.78 & 310 & 0.60 & 88 & 0.18 \\
\hline
\end{tabular}

Fuente: Argentina, GACTEC (1997).

a Ultimo año disponible.

b Incluye instituciones sin fines de lucro y educación superior privada.

c Corresponde al gasto en ciencia y tecnología, que abarca más que el gasto en investigación y desarrollo.

CUADRO 2

Investigadores en ciencia y tecnología y publicaciones en revistas internacionales ${ }^{a}$

\begin{tabular}{|c|c|c|c|c|c|}
\hline Países & $\begin{array}{l}\text { Cantidad de } \\
\text { investigadores }\end{array}$ & $\begin{array}{c}\text { Investigadores/ } \\
\text { PEA }\end{array}$ & $\begin{array}{c}\text { Cantidad de } \\
\text { publicaciones } \\
\text { (prom. anual 1992-1995) }\end{array}$ & $\begin{array}{l}\text { Cantidad de } \\
\text { publicaciones por } \\
\text { investigador }\end{array}$ & $\begin{array}{c}\text { Cantidad de } \\
\text { publicaciones/ } \text { PEA }^{b}\end{array}$ \\
\hline Estados Unidos & 962700 & 7.4 & 253347 & 0.26 & 20.27 \\
\hline Reino Unido & 140000 & 5.0 & 51840 & 0.37 & 18.51 \\
\hline Alemania & 240802 & 5.7 & 47036 & 0.20 & 11.20 \\
\hline Francia & 129780 & 4.9 & 37107 & 0.29 & 14.27 \\
\hline España & 41681 & 2.8 & 13698 & 0.33 & 9.13 \\
\hline Argentina & 22147 & 1.9 & 2306 & 0.11 & 1.92 \\
\hline Brasil & 37300 & 0.7 & 4415 & 0.12 & 0.75 \\
\hline México & 19434 & 0.6 & 2254 & 0.16 & 0.68 \\
\hline Chile & 6429 & 1.3 & 1228 & 0.19 & 2.46 \\
\hline República de Corea & 98764 & 4.9 & 1108 & 0.01 & 0.55 \\
\hline
\end{tabular}

Fuente: Argentina, GACTEC (1997).

a Ultimo año disponible.

b Medida por cada 100000 miembros de la población económicamente activa (PEA).

De todas formas, más allá de la magnitud de la inversión respectiva, en el Plan se afirma correctamente que los esfuerzos del sector privado son generalmente de corto plazo, no incluyen actividades sistemáticas de investigación científica y tecnológica y no se vinculan con las instituciones públicas de ciencia y tecnología ni se desarrollan en redes en las que participen activamente los proveedores, usuarios y clientes. Por ende, están lejos de tener la envergadura requerida para abordar los desafíos que supone la conformación de un SNI.

En segundo lugar, la Argentina está en clara desventaja respecto a los países industrializados y a la República de Corea, y en mejor situación relativa que
México, Brasil y Chile, en cuanto a proporción de investigadores en relación con la población económicamente activa (cuadro 2). En contraste con lo que ocurre en los países industrializados y en la República de Corea, la casi totalidad del personal se desempeña en organismos del sector público nacional, incluido el CONICET, y en las universidades nacionales.

A pesar de contar con recursos humanos de muy buena formación y el reconocimiento universal de los aportes de algunos investigadores y grupos de investigación científica de Argentina (el único país de la región con varios premios Nobel en ciencias), no puede soslayarse el envejecimiento de la población de inves- 
tigadores y el escaso desarrollo relativo de muchas disciplinas científicas. Como se observa en el cuadro 2, la productividad de la investigación científica medida por publicaciones en revistas internacionales no es elevada, ${ }^{10}$ en comparación con los países industrializados. No obstante, es superior a la de varios países en desarrollo, incluida la República de Corea. Asimismo, se observa una preocupante disminución relativa en el número de alumnos que cursan ciencias básicas y tecnológicas (del 40\% en 1986 al 33\% en 1996).

Por otra parte, la interacción del sector educativo con los sectores científico-tecnológicos y sobre todo con el sector productivo es aún muy limitada. La docencia se nutre en escasa medida de la investigación, y los esfuerzos de investigación en las universidades están poco articulados, tanto entre ellas como con las necesidades de los sectores productivos.

En tercer lugar, el gasto en ciencia y tecnología del sector público representó en 1996 el 0.33\% del PIB, cifra muy pequeña en una comparación internacional (cuadro 1). Por otra parte, se estima que en 1996 a la investigación básica le correspondió el $28 \%$ de ese gasto, a la aplicada el 50\% y al desarrollo experimental el $22 \%$ del gasto total en I y D. Esta composición del gasto es muy distinta a la de los países industrializados, donde el desarrollo experimental da cuenta de alrededor de las dos terceras partes de él y la investigación básica y aplicada tienen un peso relativo muy inferior al que se observa en Argentina.

Por último, en los organismos del sector público hay carencia de prioridades, significativas deficiencias en la gestión, falta de coordinación y de mecanismos de evaluación de la calidad y fuertes desequilibrios en las asignaciones presupuestarias. El $72 \%$ del presupuesto nacional en la materia se concentra en cuatro instituciones: las universidades nacionales, el CONICET, el Instituto Nacional de Tecnología Agroindustrial (INTA) y la Comisión Nacional de Energía Atómica (CNEA). El peso de esta última institución en el presupuesto nacional es un claro reflejo de la prioridad que en el pasado se dio a la energía nuclear. En contraste, mientras el sector manufacturero genera el 25\% del PIB, el Instituto Nacional de Tecnología Industrial (INTI) sólo recibe menos del 5\% del presupuesto nacional de ciencia y tecnología. Asimismo, en un país federal

${ }^{10}$ Con la información disponible resulta difícil determinar si la productividad de la investigación científica en la Argentina no es elevada debido a la escasez o a la mala asignación de los fondos o al hecho de que parte del número de investigadores que figuran en los registros correspondientes en realidad no son tales. como la Argentina, las provincias prácticamente no participan en el financiamiento público de la actividad científico-tecnológica.

Aun cuando la evaluación de las actividades del sector público en este campo es una tarea recién comenzada, la mayor parte de las actividades que hoy se realizan son de corto plazo, si bien existen instituciones que han demostrado capacidad de ejecutar proyectos de desarrollo científico y tecnológico de largo aliento. La desarticulación entre los programas de las distintas organizaciones, la falta de objetivos precisos y de mecanismos de evaluación y la concentración en la prestación de servicios de rutina y asistencia técnica son los rasgos más notables de las actividades científicas y tecnológicas del sector público.

Es evidente que el esfuerzo en ciencia y tecnología del sector público y en especial de las firmas privadas no sólo es claramente insuficiente, sino que también es desarticulado, está poco orientado a las necesidades del sector productivo, en especial de las PYME, y no genera las sinergias que sugiere el enfoque del SNI.

Tanto la larga y complicada historia previa de las instituciones científico-tecnológicas como las características que asumió el proceso de industrialización, el papel que en él desempeñaron las empresas públicas y privadas y la propia comunidad científica, y también el accionar del Estado argentino, deberían ser tomados en cuenta al tratar de comprender cómo y por qué se ha llegado a la presente situación, tarea que excede el propósito del presente artículo. ${ }^{11}$ Sin embargo, la responsabilidad principal es del gobierno nacional y, por eso, cabe referirse primordialmente a los cambios institucionales recientes y a las políticas que se han puesto en marcha para comenzar a modificar el diagnóstico.

\section{Los cambios institucionales recientes}

En su historia la Secretaría de Ciencia y Tecnología ha dependido de distintas instancias jerárquicas, siendo la Presidencia de la Nación y el Ministerio de Educación las más frecuentes. Sin embargo, nunca pudo cumplir efectivamente con la función de coordinación y planeamiento que le fue asignada en un principio. En consecuencia, las instituciones de ciencia y tecnología quedaron en general libradas a su propia suerte o a la lógica del sector con el cual estaban más relacionadas.

\footnotetext{
${ }^{11}$ Véase un análisis de este tema en Chudnovsky y López (1995).
} 
A partir de julio de 1996, dicha Secretaría forma parte del Ministerio de Cultura y Educación. ${ }^{12}$ Su función política y sus funciones de coordinación y planificación han adquirido mayor jerarquía desde la creación del GACTEC como ámbito de tratamiento de las cuestiones científico-tecnológicas en los ministerios más relevantes y por responsabilidad que le cabe en la elaboración del Plan. Asimismo, se ha creado una Comisión de Gestión Interinstitucional, integrada por todos los organismos de ciencia y tecnología del sector público nacional (exceptuadas las universidades).

Por otra parte, para involucrar a las provincias en la determinación de las prioridades regionales se ha creado el Consejo Federal de Ciencia y Tecnología (СОFЕсут) presidido por el propio Secretario e integrado por los máximos responsables de este tema en las 23 provincias y en la ciudad de Buenos Aires.

A diferencia de los Estados Unidos y de varios países latinoamericanos, en la Argentina no había una institución dedicada exclusivamente a la promoción y fomento de la investigación científica y/o el desarrollo tecnológico, puesto que el CONICET es una institución ejecutora que también cumple funciones de promoción y fomento. Esto motivó la creación de la Agencia Nacional de Promoción de la Ciencia y la Tecnología.

Además de fortalecer los mecanismos de promoción y hacerlos accesibles a todos los grupos de investigación con independencia de la institución a que pertenecen, la creación de la Agencia apunta al reordenamiento y mejor coordinación de los instrumentos previamente vigentes. Para ello cuenta con dos fondos: el FONCYT y el FONTAR.

El FONCyт, mediante concursos públicos, subvenciona: i) proyectos de investigación científica y tecnológica (de hasta 25000 pesos por año) a cargo de grupos de investigadores que se desempeñen en instituciones públicas o privadas sin fines de lucro; los resultados de estos proyectos son a priori publicables en revistas de circulación abierta; ii) proyectos de investigación y desarrollo cuyos resultados son a priori bienes públicos, pero que pueden estar sujetos a condiciones de confidencialidad comercial, reservándose el adoptante la prioridad para adquirirlos; estos proyectos (de hasta 1200000 pesos) son concertados entre la empresa interesada y la institución sin fines de lucro que realiza la investigación y deben contar con financiamiento del adoptante.

12 Además del conicet, de la Secretaría de Ciencia y Tecnología también depende la Comisión Nacional de Energía Atómica.
El FONTAR financia proyectos de innovación y modernización tecnológica cuyos resultados son apropiables y que apuntan a mejorar la competitividad de las empresas productoras de bienes y servicios. Este fondo reúne los distintos instrumentos que con esta finalidad estaban dispersos, como la Ley 23877 y el Programa BID de Modernización Tecnológica. Los clientes del FONTAR son las empresas innovadoras y también las instituciones sin fines de lucro que deseen equiparse para mejorar su capacidad de asistencia técnica al sector privado.

La propia concepción, elaboración y discusión pública del Plan es un cambio institucional importante. El Plan es básicamente un programa de trabajo caracterizado por su flexibilidad, que le permite incorporar anualmente nuevas iniciativas de política, y por su naturaleza multidimensional, puesto que abarca tanto políticas de carácter horizontal como políticas sectoriales, regionales y temáticas.

Dada la falta de coordinación y planificación de los esfuerzos científico-tecnológicos y los conflictos de intereses que pueden surgir en instituciones que ejecutan y a la vez promueven investigaciones, los cambios descritos no sólo tienen una buena dosis de sentido común, sino que se inscriben en la dirección sugerida por el enfoque del SNI. Por supuesto que sus bondades o defectos sólo podrán verse en su ejecución práctica, a través de las medidas de política que se indican en el Plan.

\section{Las principales medidas de política y sus efec- tos en el sector público}

Para comenzar a revertir la situación descrita, el Plan se propone mejorar, aumentar y hacer más eficiente el esfuerzo nacional en ciencia, tecnología e innovación, promoviendo un mayor esfuerzo del sector privado y de las provincias a través de la cofinanciación de proyectos por las empresas privadas y las autoridades provinciales.

En lugar de centrarse casi exclusivamente en la oferta, como había sido tradicional, las políticas que se plantean en el Plan se proponen orientar los esfuerzos nacionales y regionales en ciencia, tecnología e innovación en función de las demandas del sector productivo y de las necesidades sociales y regionales del país. Al mismo tiempo, se inspiran en el enfoque del SNI y buscan promover la articulación y los vínculos entre los actores e instituciones del sector público y privado que participan en el proceso de generación, difusión y absorción de conocimientos e innovaciones. 
El Plan es mucho más específico en lo que respecta a las políticas horizontales que a las temáticas, sectoriales y regionales y por ello nos concentraremos en las primeras. En esta subsección nos referiremos a las que conciernen fundamentalmente al sector público, y en la próxima a las que tratan de inducir el proceso de innovación en el sector privado.

De todas formas caben algunas observaciones respecto a la problemática sectorial, regional y temática. Dado que la demanda de ciencia, tecnología e innovación deriva de la demanda de los bienes y servicios económicos y sociales que las incorporan, ellas deberían ser un componente central de las políticas sectoriales, como bien se afirma en el documento del Plan.

Sin embargo, mientras que en actividades como la agroalimentaria y la minera se han hecho diagnósticos correctos y se han esbozado algunas medidas de política, esto está lejos de ocurrir en sectores de tanta relevancia como el resto de la industria manufacturera, el medio ambiente, la educación y la salud. En ese sentido, el desigual grado de elaboración de las prioridades sectoriales en el Plan es un reflejo del interés con que los responsables respectivos han encarado la tarea $y$, en cierta medida, de la eficacia del GACTEC como mecanismo de coordinación y planificación.

De todas formas, vale la pena tener en cuenta que, a diferencia del pasado, en los años noventa el gobierno nacional ha sido poco proclive a formular e implementar políticas sectoriales, siendo tal vez el sector automotriz, la minería y el Plan Espacial (aunque éste último más que un sector es una actividad) las excepciones más notables en el sector productivo .

A nivel regional, en el Plan se incorporan los resultados de un Programa Piloto de Detección de Necesidades en materia de aplicaciones y conocimientos científicos y tecnológicos, que están aún lejos de constituir lineamientos de política para orientar los esfuerzos provinciales en ciencia y tecnología y mucho menos para conformar sistemas regionales de innovación.

La biotecnología y los estudios sobre el mar argentino son las dos únicas áreas temáticas que se abordan en el Plan. Mientras que en la primera se plantean prioridades para la investigación y se sugieren algunas actividades como la implementación de un sistema de valorización de proyectos biotecnológicos y el fomento de microempresas y pequeñas empresas a través de un sistema de incubadoras, en la segunda se sugieren prioridades para la asignación de fondos de la Agencia.

Si bien dentro de las políticas horizontales del Plan se sugieren algunas medidas para tener mejor acceso a la información satelital y a Internet, no se plantean políticas para promover esfuerzos endógenos en microelectrónica, informática, telecomunicaciones o nuevos materiales, tecnologías genéricas que abundan en la mayor parte de los documentos oficiales de ciencia y tecnología en países industrializados y en desarrollo. En el Plan 1999-2001 se ha decidido avanzar en el tema de la microelectrónica para intentar concentrarse en sus aplicaciones, a pesar del escaso interés que existe en la Argentina por estas tecnologías genéricas, excepto como meros usuarios.

Las principales medidas de política horizontal respecto al sector público apuntan a aumentar los fondos disponibles, a producir cambios en la gestión de los organismos respectivos y a modificar la forma de asignar fondos para investigación, introduciendo mecanismos competitivos.

En el presupuesto nacional de 1998 se prevé un aumento del $12.6 \%$ en el crédito para los organismos públicos de ciencia y tecnología, que ascenderá a 881 millones de pesos. El aumento beneficia especialmente al Instituto Nacional del Agua y del Ambiente (INA), al INTA, al INTI, al Servicio Geológico Minero Argentino (SEGEMAR) y al CONICET.

Al mismo tiempo, se les exige a todos los organismos que formulen planes estratégicos donde deberán identificar con claridad las prioridades institucionales, las metas, los indicadores de resultados e impacto, así como los mecanismos de autoevaluación. En el Plan se propone que los organismos que hayan formulado Planes Estratégicos y de Transformación en función de los lineamientos del Plan Nacional Plurianual y que se sometan al proceso de evaluación externa que se va a realizar en el período 1998-2000, accedan a condiciones de gestión más flexibles que las actuales y que contemplen, entre otras cosas, la posibilidad de incorporar incentivos para el personal basados en el logro de metas y resultados. Para establecer una mayor vinculación de los organismos de ciencia y tecnología con los usuarios y para incitar a su personal científico a participar en tareas tecnológicas, las modificaciones en cuestión son imprescindibles.

Se trata de poner en marcha una reestructuración significativa de los organismos públicos del rubro, cuyo desempeño ha sido muy desigual y que, en general, carecen de metas y objetivos definidos en función del nuevo contexto en que operan la economía y la sociedad argentinas. Aunque evidentemente es prematuro abrir juicio sobre un proceso recién iniciado, tanto la compleja historia previa de los organismos y las dificultades presupuestarias con que se desenvuelven, así 
como la desigual voluntad política que parece existir dentro del GACTEC, arrojan dudas sobre el éxito que puede llegar a tener un proceso tan complicado.

Sin embargo, es importante reconocer que el INTI, uno de los organismos cuyo funcionamiento y organización pusimos en tela de juicio en un detallado estudio previo (Chudnovsky y López, 1995), parece haber comenzado a superar algunas de sus deficiencias históricas, a definir mejor su accionar en el nuevo contexto, a cambiar el perfil generacional de su personal y a fortalecer tanto las actividades horizontales como la vinculación de los centros sectoriales con los usuarios. Asimismo, la Comisión Nacional de Actividades Espaciales (CONAE) tiene un plan estratégico en el que define claramente sus metas y tareas y ha sido uno de los pocos organismos públicos que han concretado acciones de auditoría y evaluación.

En forma simultánea con el lanzamiento de este proceso de reforma en los organismos públicos de ciencia y tecnología, parte de los fondos de los que disponga la Agencia se van a asignar a proyectos de investigación presentados por estos organismos (y fundaciones sin fines de lucro) a través de mecanismos de competencia.

Esto significa que, además de los fondos que reciban del presupuesto nacional, tales organismos van a poder acceder a recursos adicionales si los proyectos de investigación que presenten son bien evaluados en función de su calidad (juicio por pares) y pertinencia (impacto en el desarrollo económico y social y en el sector educativo, y adecuación a las prioridades establecidas en el Plan). ${ }^{13}$ Como a su vez los proyectos subvencionados por la Agencia deben ser cofinanciados por sus ejecutores, por el sector privado o por las provincias, es preciso que los fondos adicionales se asignen en forma competitiva y potencien los efectos del financiamiento público.

Aunque poco significativos frente al presupuesto del sector público nacional que, como dijimos, es de 881 millones de pesos, los fondos con que va a contar el FONCyт en 1998 no son despreciables. Tendrá un presupuesto de 36 millones de pesos que, con los recursos adicionales que aporten los ejecutores de los proyectos, se elevará a 44.5 millones. A la vez, se

\footnotetext{
13 Estos criterios de asignación de recursos son los que más han generado resistencias y fuertes críticas al Plan en importantes segmentos de la comunidad científica (como el Foro de Sociedades Científicas Argentinas) que obviamente preferirían seguir con las prácticas del pasado dentro del CONICET, beneficiosas básicamente para sus integrantes.
}

plantea que el FOnCyt va a asignar un $75 \%^{14}$ de su presupuesto según las prioridades establecidas en el Plan y el resto va a ser destinado a proyectos de investigación en las demás disciplinas o áreas temáticas.

Con el propósito de fomentar las vinculaciones que son centrales en el enfoque del SNI, en el Plan se plantea que el FONCyT dará prioridad a los proyectos que tiendan a formar redes de investigación, presentados en forma conjunta por investigadores de una misma región, de diferentes regiones del país o con instituciones de otros países, en el marco de los distintos convenios de cooperación internacional.

La introducción de mecanismos competitivos para asignar fondos públicos a la investigación es sin duda un cambio en las reglas del juego e impone una gran responsabilidad a la Agencia, cuyo proceso de aprendizaje está recién iniciado y cuyas decisiones afectarán a intereses creados dentro de la comunidad científica.

\section{Las medidas dirigidas al sector privado}

Además de propiciar una mayor participación de las empresas en los proyectos de investigación y desarrollo que financia el FONCYT, el FONTAR va a seguir promoviendo los créditos vigentes de reintegro obligatorio para empresas a través del Banco de la Nación Argentina y otros instrumentos financieros que tiene a su disposición. ${ }^{15} \mathrm{Al}$ mismo tiempo, su desempeño se va a fortalecer con el lanzamiento de un programa de consejeros tecnológicos para las PYME y con un mecanismo de crédito fiscal para fomentar un mayor esfuerzo en actividades tecnológicas por parte de las empresas privadas.

Si bien la unificación de los instrumentos financieros vigentes dentro del FONTAR ha sido una decisión sensata, a la luz de la experiencia de los últimos años es difícil ser optimista respecto al impacto que ello puede tener en el proceso de modernización tecnológica de las PYME.

De los instrumentos previstos en la Ley 23877 para promover la innovación tecnológica, sólo se pudieron implementar, en forma bastante errática, los créditos a proyectos de I y D presentados por empre-

\footnotetext{
${ }^{14}$ A su vez el $75 \%$ se distribuirá de la siguiente forma: $25 \%$ a proyectos en los temas prioritarios de salud, educación y medio ambiente; $25 \%$ a proyectos en los sectores agroalimentario, industrial y minero y el $25 \%$ a proyectos que reflejen las prioridades acordadas con las provincias.

${ }^{15}$ Entre los cuales se encuentran subsidios de hasta 100000 pesos para proyectos de alto riesgo técnico presentados por PYME que cofinancien como mínimo un $50 \%$ del costo total del proyecto.
} 
sas o unidades de vinculación tecnológica. ${ }^{16}$ Se trata de créditos con tasa de interés subsidiada que concede directamente la Secretaría de Ciencia y Tecnología y que exigen fianzas como garantía de reembolso. Desde 1993 a 1997 se concedieron 25 créditos a nivel nacional por un monto total de 10.3 millones de pesos y una inversión total de 16.3 millones. La concesión de créditos muestra una tendencia descendente: de 13 en 1993 a 8 en 1996 y sólo uno en 1997. Además de los problemas que se han suscitado para disponer de los fondos, estos créditos se han caracterizado por ser en alta proporción incobrables: $45 \%$.

Los créditos de reintegro obligatorio que concede el Banco de la Nación Argentina con fondos propios y del Banco Interamericano de Desarrollo están destinados a proyectos de modernización tecnológica que son relativamente sencillos y de bajo riesgo. Los préstamos se conceden por un monto máximo de 2 millones de dólares. La tasa de interés es variable y se requieren garantías reales. Desde 1995 a la fecha se han otorgado 29 créditos a pequeñas y medianas empresas por un monto total de 17.7 millones de dólares, para inversiones totales de 48 millones.

Si bien se observa una tendencia ascendente en el otorgamiento de estos créditos, su escaso número se debe a varios factores: el elevado endeudamiento de las PYME; la exigencia de garantías reales por parte del Banco de la Nación Argentina; la poca experiencia de este banco en conceder préstamos distintos de los tradicionales destinados a inversiones físicas y en los cuales se privilegia la capacidad de repago, y la imposibilidad de financiar el capital de trabajo y de conceder préstamos a empresas nuevas.

El hecho de que, a pesar de su escasa experiencia, sea este banco la única institución financiera que se ha involucrado en préstamos de esta índole es también sintomático de una falla más profunda en el sistema financiero argentino: su desinterés en canalizar fondos para proyectos de modernización e innovación tecnológica. Este es un tema crucial que debería ser

\footnotetext{
${ }^{16}$ La figura de "unidades de vinculación tecnológica" (UVT) ha sido una innovación de la ley 23877 que, en teoría, se inspiraría en el enfoque del SNI. Las UVT se definen como entes no estatales constituidos para la identificación, selección y formulación de proyectos de I y D, transmisión de tecnología y asistencia técnica. Pueden estar relacionadas o no con un organismo público y su forma jurídica puede ser la de una sociedad comercial o la de una asociación civil. La Secretaría de Ciencia y Tecnología autoriza explícitamente el funcionamiento de las UVT, las que pese a sus potenciales virtudes como instrumentos para favorecer las interacciones entre la oferta y la demanda tecnológica, en la práctica no han tenido un papel significativo.
}

abordado en versiones futuras del Plan y discutido desde el ángulo del SNI (véase oCDE, 1995).

Teniendo presente las limitaciones de un enfoque basado exclusivamente en la oferta de préstamos, como parte de la preparación del Plan el Instituto de Industria de la Universidad Nacional de General Sarmiento ha hecho un diagnóstico de la demanda, esto es, de los desafíos tecnológicos que enfrentan las pequeñas y medianas empresas industriales. En función de ese diagnóstico e inspirado en esquemas similares de países industrializados y en el Programa Cambio Rural de la Secretaría de Agricultura, se ha planteado un Programa de Mejoramiento de la Capacidad Tecnológica de las PYME que se propone facilitar un progresivo desarrollo de la oferta de servicios tecnológicos para que éstos contribuyan efectivamente al mejoramiento competitivo de las firmas usuarias, y promover una mayor articulación entre los demandantes de servicios técnicos y los oferentes públicos y privados de ellos.

En los diversos encuentros realizados con pequeñas y medianas empresas se puso de manifiesto que sus demandas apuntan a lograr información calificada sobre tecnologías de productos y de procesos, incluyendo mecanización, mejoras de la calidad y normas técnicas. Asimismo, requieren asesoramiento especializado sobre optimización del proceso de producción, productos tecnológicamente más complejos, materiales adecuados, aseguramiento de la calidad, reconversión de la firma y búsqueda de nuevos nichos de mercados y de productos. En suma, necesitan asesoramiento destinado a mejorar sus competencias y también a satisfacer necesidades específicas de capacitación.

Por otra parte, se han puesto en evidencia las fallas de información sobre la oferta de servicios de organismos públicos, universidades, empresas y otras instituciones. En los casos en que las PYME han recurrido a estos oferentes, ha quedado de manifiesto la necesidad de que los servicios sean más flexibles y mejor adaptados a las peculiaridades de este tipo de empresas. Surgió así la demanda de contar con servicios especializados que no sólo diagnostiquen mejor los problemas tecnológicos de las PYME sino que ayuden a encontrar posibles soluciones.

Los consejeros tecnológicos son el eje del Programa de Mejoramiento de la capacidad tecnológica de las PYME y por ello nos referiremos a él como Programa de Consejerías. El papel del consejero es lograr que la empresa evalúe sus capacidades técnicas, establezca sus necesidades y busque las soluciones y alternativas que considere más útiles. El consejero amplía los elementos para la toma de decisiones y ayuda a poner en 
marcha el proceso de fortalecimiento de las capacidades. No es función del consejero suplir estas carencias, sino ayudar a superarlas.

El Programa de Consejerías apunta principalmente a desarrollar un mercado de servicios de asesoramiento tecnológico para las aproximadamente 15000 PYME industriales argentinas que operan en sectores transables. Se han previsto dos tipos de consejerías: la consejería tecnológica institucional y la consejería tecnológica individual. En el primer caso, se establecerá un esquema de consejería con pasantías de jóvenes graduados en ingeniería y carreras científicas y tecnológicas afines. Su participación se organizará a través de instituciones públicas y/o privadas sin fines de lucro (por ejemplo departamentos de ingeniería de universidades) que ofrezcan a las PYME un apoyo de consejería por medio de pasantes radicados en cada firma y supervisados por profesionales experimentados.

En el segundo caso, habrá consejeros individuales que apoyen y aconsejen a un grupo reducido de empresas en forma personal. A través de cámaras y entidades empresariales o uniones transitorias de empresas se conformarán conjuntos de una docena de PYME que dispondrán de un consejero exclusivo a través de un programa colectivo de actividades y de necesidades. Cada entidad presentará un programa de trabajo al llamado a concurso del FONTAR.

El financiamiento del programa de consejerías tecnológicas se hará con fondos de la Ley 23877 que administra el FONTAR (serían 5.4 millones de pesos en 1998), con los aportes de las empresas usuarias del servicio y con otros fondos que dispongan las entidades que van a realizar los servicios de consejería.

Indudablemente, el Programa de Consejerías es una buena iniciativa que se encuadra bien dentro del enfoque del SNI y se inspira en algunos elementos de las mejores prácticas internacionales (Humphrey y Schmitz, 1996, y OCDE, 1997).

En lugar de los numerosos programas existentes en la Argentina que están basados en la oferta de financiamiento o servicios no financieros a empresas individuales y que generalmente subsidian las inversiones físicas o el capital de trabajo, el Programa de Consejerías ha sido motivado por las demandas del sector productivo y apunta a vincular instituciones públicas tecnológicas y universidades con grupos de empresas y no con empresas individuales. El subsidio a las firmas para facilitar el pago de los servicios de consejería va a permitir que las PYME incorporen ingenieros a sus planteles de personal (en muchos casos por primera vez) y empiecen a valorizar la importancia de sus servicios.

Al mismo tiempo, el Programa de Consejerías ofrece oportunidades de empleo a ingenieros jóvenes y facilita el contacto con la realidad del sector productivo desde el inicio de la carrera profesional. También hace que los profesionales con experiencia se vinculen mejor con las necesidades específicas del sector productivo, supervisen las prácticas de los jóvenes graduados y enriquezcan el propio trabajo dentro de sus instituciones con información de primera mano de lo que ocurre en la realidad fabril. El hecho de que los consejeros no vengan sólo ocasionalmente a las firmas, sino que se incorporen en forma sistemática en la vida fabril, debería hacer más fluida la transmisión y desarrollo de conocimientos tácitos. A la vez, una misión central de los consejeros es facilitar a las empresas el acceso a los servicios de las instituciones científicas y tecnológicas del sector público y hacer que éstas tengan mucho más en cuenta las demandas específicas del sector productivo.

Sin embargo, no es posible soslayar las dificultades que puede enfrentar la puesta en marcha de este programa. Además de la falta de experiencia del FONTAR $y$, en general, del país en este tipo de instrumentos de política, las empresas pueden mostrarse reacias a participar por diversas razones: aversión a trabajar en grupos, desconfianza hacia la capacidad de los consejeros o de las instituciones de proveer un buen servicio, dificultades para financiar la parte de los servicios que no está subsidiada por el Estado, etc. Asimismo, las universidades y otras instituciones pueden no estar suficientemente motivadas para encarar tareas a las que no están acostumbradas y en las cuales los beneficios directos no son significativos. A su vez, los conocimientos que tienen los jóvenes graduados pueden no resultar adecuados para las tareas que se plantean y las PYME pueden sentirse muy pronto decepcionadas. Por otra parte, como se plantea en el Plan, el Programa de Consejerías debería interactuar estrechamente con los diversos programas hoy vigentes para las PYME. ${ }^{17}$ Este deseo choca con una realidad difícil de modificar, en la que abundan la dispersión de esfuerzos y la falta de coordinación en esta materia.

Si sobre la marcha se van superando algunos de estos obstáculos iniciales y el Programa de Consejerías

\footnotetext{
${ }^{17}$ En la parte correspondiente del Plan se enumeran 31 instrumentos vigentes dirigidos a las PYME, de los cuales 13 tienen una alta vinculación con el Programa de Consejerías.
} 
gana experiencia y credibilidad, sería oportuno tener en cuenta otro tipo de problemas que pueden aparecer en los mecanismos para pequeñas y medianas empresas guiados por la demanda. En un interesante estudio sobre la reciente experiencia de la Corporación de Fomento (CORFO) en Chile para poner en práctica un esquema de ese tipo, se hace notar que los costos de acceso al sistema de fomento llevan a que un núcleo restringido de empresas tenga, por definición, acceso preferente a él, siendo estas firmas las más dinámicas y las que, en teoría, menos necesitan del apoyo público. Por otra parte, como lo que está en juego son activos tácitos sujetos a incompleta especificación y a muy imperfecta transferibilidad, es difícil que aquellas empresas beneficiarias tengan incentivos para transmitir a terceros su propia experiencia, o incluso posibilidades de hacerlo, con lo cual se reducirían fuertemente las externalidades (Dini y Katz, 1997).

En lo que respecta a otros instrumentos de política para impulsar tanto a las grandes como a las pequeñas empresas nacionales y a las filiales de firmas extranjeras a realizar esfuerzos en investigación y desarrollo con su propio personal calificado o en contrato con instituciones de investigación, se ha previsto un crédito fiscal de 20 millones de pesos en el presupuesto nacional de $1998 .{ }^{18}$

Para tratar de impedir los abusos a que da lugar este tipo de incentivos, los certificados de crédito fiscal se adjudicarán por licitación a los proyectos de investigación y desarrollo que se concursen ante la Agencia. Dichos certificados podrán ser utilizados por sus titulares para cancelar sus obligaciones emergentes del impuesto a las ganancias, en un porcentaje decreciente según el monto anual de dicho impuesto.

En la medida en que contribuyan a la financiación de hasta el 50\% de los costos de ejecución de los proyectos, los fondos públicos servirán de palanca para potenciar el financiamiento privado para I y D. De esa forma, se estima que el crédito fiscal va a generar un aporte adicional del sector privado estimado en 30 millones de pesos.

Con el crédito fiscal la Argentina se pone a tono con muchos otros países —en especial Brasil—que utilizan este instrumento, aceptado por la Organización Mundial del Comercio, para estimular al sector privado a realizar esfuerzos en materia de investigación y desarrollo. A diferencia de los incentivos financieros

\footnotetext{
${ }^{18}$ En realidad se completa una asignatura pendiente: reglamentar el crédito fiscal que establece el artículo 9 de la ley 23877 .
}

que están pensados fundamentalmente para las PYME, el crédito fiscal, además de ser útil para aquellas firmas que cumplen con sus obligaciones impositivas, seguramente va a ser de interés para las grandes empresas.

Según las estimaciones disponibles, el gasto del sector privado en I y D en 1996 fue de 369 millones de pesos, de modo que el impacto que el crédito fiscal puede llegar a tener sobre el comportamiento del sector privado es reducido y probablemente sólo beneficie a las firmas grandes que ya tienen actividades de esa índole. De todas formas, dicho crédito puede llegar a ser un aliciente para que las empresas hagan más en esa materia, como lo ilustra la reciente experiencia brasileña con la aplicación de la ley 8661/93, y tener así efectos multiplicadores.

Sin negar la importancia de una macroeconomía estable y de elevado crecimiento, y reconociendo el valor de los incentivos financieros y fiscales, de los proyectos de investigación y desarrollo que financia el Foncyt y del Programa de Mejoramiento de la Capacidad Tecnológica de las PYME, no cabe duda que este contexto y estos instrumentos están lejos de tener la envergadura suficiente para modificar de modo sustancial el comportamiento de las grandes y pequeñas firmas en materia tecnológica.

Para enfrentar el cambio en las reglas del juego que supone competir en economías más abiertas al comercio internacional y a la entrada de nuevos competidores, las empresas sobrevivientes en general han redoblado sus esfuerzos tecnológicos para ganar eficiencia y lograr mejoras de productividad y calidad. Sin embargo, este proceso ha sido muy heterogéneo en lo que toca a actividades, tamaño de las firmas y localización geográfica.

Mientras que la mayoría de las PYME que han sobrevivido lo han hecho tratando de mejorar la productividad y la calidad, un número importante de firmas (sobre todo grandes) no sólo han invertido en bienes de capital importados, sino que también han recurrido a licencias y asistencia técnica del exterior o han sido compradas por inversores extranjeros. Presumiblemente, estas firmas también han hecho esfuerzos por absorber esas tecnologías provenientes del exterior y por llegar a adaptarlas y generar algunas innovaciones en materia de productos y de procesos. Sin embargo, la información disponible para examinar este complejo proceso de destrucción creadora es muy fragmentaria y sólo permite dar cuenta del fenómeno en algunas empresas extranjeras y grandes empresas nacionales. 
A principios de los años noventa, un grupo de 39 filiales de empresas transnacionales que operaban en diversos sectores industriales tenían un gasto promedio en I y D del orden del 1\% sobre las ventas (Kosacoff y Bezchinsky, 1993), algo superior a lo estimado para el conjunto del sector manufacturero argentino. Nuestros trabajos sobre IED han puesto de relieve que los esfuerzos endógenos en las filiales se concentran en la capacitación del personal y las mejoras en calidad y productividad. De las empresas privatizadas, sólo una de las prestadoras telefónicas mantiene un laboratorio de investigación y desarrollo, no vinculado al de la casa matriz, para cuestiones operativas. En las firmas manufactureras los mayores esfuerzos en este terreno (generalmente inferiores al $1 \%$ de la facturación) los encontramos en los fabricantes de equipos de telecomunicaciones y en algunas empresas del rubro alimentario orientadas a la exportación de productos básicos (Chudnovsky, Porta, López y Chidiak, 1996).

Por otra parte, los esfuerzos dirigidos a mejorar la capacitación tecnológica de los proveedores sólo han tenido cierta envergadura en la industria automotriz y, en muchos casos, han significado la adquisición de empresas de autopartes locales por firmas extranjeras. Las externalidades de tipo tecnológico generadas por la presencia de empresas transnacionales parecen ser débiles, dadas la poca envergadura de las actividades innovadoras en las filiales y las escasas vinculaciones tecnológicas de estas firmas con proveedores o institutos de investigación locales.

En el sector farmacéutico se registran esfuerzos significativos en investigación y desarrollo por parte de algunas firmas locales. En otras áreas de actividad los gastos de estas firmas son similares o inferiores a los que efectúan las filiales de empresas transnacionales. En los pocos conglomerados económicos que tienen actividades de esa índole, estos gastos son inferiores al $1 \%$ de su facturación. Mientras que las alianzas estratégicas con empresas internacionales son frecuentes en estos conglomerados, es dudoso que haya muchos acuerdos en que se dé prioridad a las actividades de innovación tecnológica. No obstante, éste es un tema que merecería ser estudiado.

El hecho de que el sector privado gaste poco en I y $\mathrm{D}$ es, en parte, una consecuencia del tipo de rubros en que se concentran las inversiones productivas en la Argentina. Se trata en general de actividades basadas en los recursos naturales o en las cuales las economías de escala son importantes, que a nivel internacional, tampoco registran gastos significativos en la materia. Lo mismo ocurre a nivel internacional en las activida- des donde se han concentrado las privatizaciones (agua, electricidad, gas, petróleo). Sólo el sector de telecomunicaciones hace uso muy intensivo de I y D, pero esto no ocurre en la Argentina.

Sin embargo, los eslabonamientos hacia atrás o hacia adelante de los sectores donde se han concentrado las inversiones podrían dar lugar a actividades con uso intensivo de conocimientos; por otra parte, se podrían revitalizar algunos segmentos de la industria de maquinaria y equipamiento especializados, así como impulsar algunas actividades basadas en el acervo de personal científico que tiene el país.

Es posible que las empresas nacionales y extranjeras vayan lenta y espontáneamente aumentando sus actividades innovadoras e incluso invirtiendo en rubros que hacen uso intensivo de conocimientos. En ese caso, se podría argumentar que, más allá de una macroeconomía en crecimiento y los instrumentos horizontales mencionados más arriba, el laissez faire sería la política más indicada para el sector privado.

Sin embargo, si se estima que se debería acelerar este proceso e impulsar tales actividades mediante políticas específicas, no parece posible ignorar el ámbito sectorial. Allí es justamente donde se ponen de relieve las debilidades de la nueva política científica y tecnológica. Sólo en el caso de la minería, donde existe una política sectorial definida, y en la producción agroalimentaria, donde se intenta comenzar a definir líneas de política, la variable tecnológica empieza a incorporarse explícitamente en la dinámica sectorial.

En el resto de la industria manufacturera, en cambio, la variable tecnológica ha sido omitida en las decisiones que el gobierno nacional ha tomado en los regímenes de adecuación de varios sectores industriales dentro del MERCOSUR y en el tratamiento que se ha dado a la industria local de maquinaria y equipo. ${ }^{19} \mathrm{En}$ el régimen para la industria automotriz se ha dejado que las empresas transnacionales y/o sus licenciatarios nacionales procedan en materia tecnológica según sus

\footnotetext{
${ }^{19}$ Para favorecer el proceso de inversión y la modernización tecnológica de los usuarios, en 1993 se decidió aplicar un arancel cero a los bienes de capital importados y compensar a los fabricantes locales con un subsidio a los compradores de sus equipos equivalente al valor del arancel. Además de las tardanzas en conceder el subsidio respectivo, que agravaron aún más las dificultades de esa rama para adaptarse a las nuevas reglas del juego, el potencial de desarrollo tecnológico de la industria local de bienes de capital estuvo completamente ausente en la política gubernamental. A partir de 1995 se elevaron los aranceles al sector de bienes de capital dentro de las convergencias acordadas en el MERCosur, pero sigue sin haber política alguna para un sector tan importante dentro del SNI.
} 
intereses, sin tratar de obtener demasiadas externalidades en cuanto a desarrollo de proveedores, gestión ambiental, capacitación de personal y vinculación con los institutos tecnológicos. ${ }^{20}$

Como dijimos más atrás, en sectores cruciales para el SNI como salud, educación y medio ambiente el tema científico y tecnológico aparece mencionado en forma más retórica que efectiva en las políticas que se indican en el Plan.
Mientras que son evidentes los esfuerzos del gobierno por promover actividades tradicionales basadas en los recursos naturales - como la producción minera, agroindustrial, de gas y de petróleo-, brillan por su ausencia las iniciativas para promover actividades que hacen uso intensivo de conocimientos (con excepción de lo que se esboza en el Plan respecto a la biotecnología) en los sectores productivos de bienes y de servicios.

\section{IV}

\section{Observaciones finales}

En una economía estable y en crecimiento, la reorganización tardía pero al fin en marcha del sector de ciencia y tecnología, así como la concepción, el diagnóstico y las políticas horizontales que se plantean en el Plan, son elementos ciertamente positivos.

Puesto que centra buena parte de las políticas públicas en promover interacciones de la demanda y la oferta, del sector público y el privado, de las instituciones científicas y tecnológicas y de los usuarios, de los insumos que provienen del exterior y de los esfuerzos locales, de las actividades provinciales y de las prioridades nacionales, el Plan se inspira claramente en el enfoque del SNI.

Al incrementar el financiamiento y a la vez comenzar a modificar las normas para asignar recursos públicos a la investigación (creación de la Agencia, con fondos competitivos y evaluación por pares); al impulsar planes estratégicos y mecanismos de evaluación en los organismos públicos de ciencia y tecnología, y al tratar de establecer algunas prioridades en la asignación de fondos, las políticas promueven modificaciones institucionales que pueden vigorizar el anémico complejo científico-tecnológico y comenzar a aminorar sus más obvias fallas sistémicas.

Asimismo, al poner en marcha el crédito fiscal para la I y D y tratar de articular mejor los incentivos financieros con la modernización tecnológica vigente, y sobre todo al lanzar el Programa de Consejeros tecnológicos, el Plan trata de atender mejor las demandas de las PYME y comenzar a revertir la renuencia de

\footnotetext{
${ }^{20}$ La Secretaría de Industria lanzó en 1994 un interesante Programa de Desarrollo de Proveedores que, por razones que debieran investigarse, no parece haber tenido éxito.
}

las empresas a realizar inversiones en innovación tecnológica que complementen los insumos venidos en forma masiva del exterior.

Lamentablemente, estas políticas horizontales sólo están bien complementadas con esfuerzos sectoriales en la minería y, tal vez, en la producción agroalimentaria. Pero están lejos de encontrar eco en las propuestas sectoriales para el resto de la industria manufacturera, salud, educación y medio ambiente.

Esto nos lleva a los aspectos negativos más evidentes que conspiran contra los objetivos y políticas del Plan. Las fallas que tienen en la Argentina el sistema financiero para financiar inversiones de largo plazo en activos intangibles, el sistema educativo para vincularse con las necesidades del sector productivo y las instituciones científicas para interactuar con el sistema educativo y el productivo, son muy profundas. Estas fallas se mencionan en el Plan pero están lejos de recibir la atención que necesitan para comenzar a corregirlas.

Si bien el GACTEC parece ser una buena solución institucional para abordar los problemas de corte transversal que presenta la política de ciencia y tecnología, todavía está lejos de funcionar como un ámbito de articulación de la política científica y tecnológica con las políticas sectoriales, y menos aún de diseño de una visión de largo plazo que oriente los esfuerzos de inversión en activos tangibles e intangibles y de formación de recursos humanos en el país. Para ello sería necesario, como mínimo, que el nivel de compromiso con la problemática científica y tecnológica que tiene la actual conducción de la Secretaría de Ciencia y Tecnología se repitiese en los otros ministerios y secretarías de Estado involucrados. 
Sin embargo, la discusión pública del Plan en la que han participado alrededor de un millar de personas en diversos talleres y seminarios lo ha enriquecido en su versión definitiva y es previsible que en las revisiones anuales sucesivas sea perfeccionado y algunas de sus omisiones empiecen a corregirse. Al mismo tiempo, es evidente que se requiere tiempo para que se hagan sentir los efectos de los cambios en las reglas del juego y de las políticas propuestas.

De todas formas, se impone la cautela al tratar de predecir el efecto que las actuales políticas pueden llegar a tener en la reversión de la crisis que afecta al sector público en este campo y en la modificación de los patrones de comportamiento del sector privado.

En la Argentina, la larga y frustrante historia de las políticas de ciencia y tecnología muestra más fracasos que éxitos; y por otro lado, el laissez faire de los años noventa ha sido parcialmente exitoso y es apoyado por parte del gran empresariado local y extranjero. Ambas cosas son factores de peso que conspiran contra el éxito de las iniciativas en marcha. Al mismo tiempo, y pese a sus sugerentes planteamientos, el enfoque del SNI revela profundas ambigüedades normativas y conceptuales que restringen su aplicación práctica.

En estas circunstancias, el incipiente nivel de compromiso con el tema científico-tecnológico en el gabinete nacional refleja problemas de larga data en el país. En la sociedad civil, y en particular en los sectores productivos, no hay conciencia de lo importante que puede llegar a ser la contribución de la ciencia y la tecnología al desarrollo económico y social del país. En las grandes empresas nacionales y extranjeras se da mucho mayor importancia a los insumos que provienen del exterior que a esfuerzos endógenos que vayan más allá de la correcta gestión de las instalaciones productivas y de la calidad de la producción. Asimismo, las actividades que realizan los científicos y tecnólogos argentinos son poco valoradas por la sociedad y los sectores productivos. Tampoco ellos han hecho, en general, muchos esfuerzos por vincular sus proyectos de investigación a las profundas y cambiantes necesidades del país.

Pese a los límites estructurales que enfrentan las políticas actuales, el diagnóstico de la situación argentina en este campo será más certero y las posibilida- des de mejorar y expandir las políticas públicas correspondientes se acrecentarán si, a través de investigaciones futuras, se comienza a clarificar una serie de interrogantes.

Primero, es necesario seguir y analizar con detenimiento la forma en que se están poniendo en práctica las iniciativas lanzadas y, en especial, la reorganización de los organismos de ciencia y tecnología, el manejo de los fondos competitivos del FONCyT, el crédito fiscal y el Programa de Consejeros tecnológicos del FONTAR, y las políticas de minería y de producción agroalimentaria.

Segundo, los resultados de la encuesta sobre la conducta tecnológica de las empresas industriales argentinas permitirán examinar la magnitud y naturaleza de los esfuerzos de innovación en el sector privado, según se trate de pequeñas y medianas empresas o grandes firmas —nacionales y extranjeras-, y aclarar en qué medida los diversos insumos provenientes del exterior complementan los esfuerzos locales en diferentes ramas del sector manufacturero. Asimismo, va a ser importante estudiar el tipo de interacciones que las empresas han ido estableciendo en el país con diversos agentes e instituciones locales y extranjeros.

Tercero, el potencial de desarrollo de actividades que hacen uso intensivo de conocimientos en la Argentina merece ser estudiado con detenimiento; también se debe analizar la factibilidad de aplicar políticas que se han seguido en otros países para impulsar este tipo de actividades (incubadoras de empresas, parques de innovación, etc.).

Cuarto, habría que examinar las fallas del sistema financiero argentino y la posibilidad de corregirlas para inducir un mayor financiamiento a inversiones intangibles.

Y, por último, los problemas que enfrenta la educación superior y técnica y las posibilidades que tiene de formar los recursos humanos que requiere el SNI confirman un tema central que aún no ha sido encarado con la debida profundidad. La formación de recursos humanos para una economía basada cada vez más en los conocimientos exige estudios detallados no sólo de la oferta sino sobre todo de la demanda, en función de escenarios a mediano y largo plazo del desarrollo económico y social del país. 


\section{Bibliografía}

Adler, E. (1987): The power of ideology. The quest for technological autonomy in Argentina and Brazil, University of California Press, Berkeley.

Argentina, GACTEC (Gabinete Científico-Tecnológico) (1997): Plan nacional plurianual de ciencia y tecnología, 1998-2000, Buenos Aires.

Argentina, Ministerio de Economía y Obras y Servicios Públicos, Secretaría de Política Económica (1997): Informe económico. Segundo trimestre de 1997, año 6, $\mathrm{N}^{\circ}$ 22, Buenos Aires.

Carlsson, B. (ed.) (1995): Technological Systems and Economic Performance: The Case of Factory Automation, Dordrecht, Países Bajos, Kluwer Academic Publishers.

CEP (Centro de Estudios para la Producción) (1997): Notas de la economía real, $\mathrm{N}^{\circ}$ 4, Buenos Aires, Ministerio de Economía y Obras y Servicios Públicos, Secretaría de Industria, Comercio y Minería, octubre.

Chudnovsky, D. y A. López (1995): Política Tecnológica en la Argentina ¿Hay algo más que laissez faire?, Documentos de trabajo, $N^{\circ} 20$, Buenos Aires, Centro de Investigaciones para la Transformación (CENIT).

Chudnovsky D., F. Porta, A. López y M. Chidiak (1996): Los Límites de la apertura, Buenos Aires, CENIT/Alianza Editorial.

Dahlman, C y R. Nelson (1993): Social absorption capability, national innovation systems and economic development, Maastricht, Países Bajos, Universidad de las Naciones Unidas, Instituto de Nuevas Tecnologías.

David, P. y D. Foray (1995): Accessing and expanding the science and technology knowledge base, STI Review. Science and Technology Industry, № 16, París, Organización de Cooperación y Desarrollo Económicos (OCDE).

Dini, M. y J. Katz (1997): Nuevas formas de encarar las políticas tecnológicas en América Latina, REDES. Revista de Estudios Sociales de la Ciencia, vol. 4, $\mathrm{N}^{\circ}$ 10, Buenos Aires, Universidad Nacional de Quilmes, Centro de Estudios e Investigaciones..

Edquist, C. (ed.) (1997): Systems of Innovation: Technologies, Institutions and Organizations, Londres, Pinter Publishers.

Edquist, C. (1997): Systems of innovation approaches-their emergence and characteristics, C. Edquist (ed), Systems of Innovation: Technologies, Institutions and Organizations, Londres, Pinter Publishers.

Freeman, C. (1988): Japan: a new national system of innovation?, G. Dosi, C. Freeman, R. Nelson, G. Silverberg y L. Soete (eds.), Technical change and economic theory, Londres, Pinter Publishers.

(1995): The national system of innovation in historical perspective, Cambridge Journal of Economics, vol. 19, $\mathrm{N}^{\circ} 1$, Londres, Cambridge Political Economy Society.
Humphrey, J. y H. Schmitz (1996): The triple C approach to local industrial policy, World Development, vol. 24, $\mathrm{N}^{\circ} 12$, Oxford, Reino Unidos, Pergamon Press.

Kosacoff, B. y G. Bezchinsky (1993): De la sustitución de importaciones a la globalización. Las empresas transnacionales en la industria argentina, B. Kosacoff y otros, El desafio de la competitividad. La industria argentina en transición, Buenos Aires, CEPAL/Alianza Editorial.

Lall, S (1992): Technological capabilities and industrialization, World Development, vol. 20, $\mathrm{N}^{\circ}$ 2, Oxford, Reino Unido, Pergamon Press.

(1995): Governments and industrialization, trabajo presentado en el seminario internacional Productivity, Technical Change and National Innovation Systems in Latin America, Marbella, Chile, CEPAL

Lundvall, B. (1992): National Systems of Innovation. Towards a Theory of Innovation and Interactive Learning, Londres, Pinter Publishers.

Mowery, D. (1993): Inward technology transfer and competitiveness: The role of national innovation systems, Berkeley, California, University of California, Haas School of Business.

Mytelka, L. (1992): Strategic partnering: Some lessons for Latin America, París, Université Paris.

(1996): Competition, innovation and competitiveness: A framework for analysis, in Mytelka, L. (ed), Competition, Innovation and Competitiveness in Developing Countries, OECD Development Centre, Paris.

Nelson, R (ed.) (1993): National Innovation Systems. A comparative analysis, Nueva York, Oxford University Press.

OCDE (1992): Technology and the Economy. The Key Relationships, París.

(1995): National Systems for Financing Innovation, París. (1996a): OCDE Programme on National Innovation Systems. Synthesis report, $\mathrm{N}^{\circ} 4$, París.

(1996b): Science, Technology and Industry Outlook 1996, París.

(1997): Diffusing Technology to Industry: Government Policies and Programmes, París.

Williamson, J. (1990): Latin American Adjustment. How Much has Happened?, Washington D.C, Institute for International Economics (IIE).

(1997): The Washington consensus revisited, L. Emmerij (ed), Economic and Social Development into the XXI Century, Washington D.C., Banco Interamericano de Desarrollo/The Johns Hopkins University Press. 